Thorax (1546), 1, 257.

\title{
THROMBOSIS OF THE SUPERIOR VENA CAVA
}

BY

\author{
E. T. RENBOURN
}

London

Complete thrombotic occlusion of the superior vena cava is rare. Ochsner and Dixon (1936) in a review of the world literature were able to collect 120 cases, of which only 10 could be termed idiopathic. The following is a case which was of exceptional interest in that there were very few symptoms, and the condition hed been present for nearly 50 years.

\section{CASE RePort}

A single woman, aged 65, was seen in August, 1940, on account of swelling of the left arm and hand.

PAST History.-As a girl she had always been healthy. Large veins had been present in her neck, chest, and abdomen as long as she could remember. They were certainly present when she was 12 years of age, and probably when she was 8 years or younger. The veins did not appear suddenly, and she did not remember ever having had swelling or blueness of the face. As she grew older the veins increased in size, but she did not think that any new ones appeared. The condition of her veins never caused her any inconvenience. Varicose veins appeared in her legs after the age of 30 , this condition being very common in her family. At the age of 45 a movable lump appeared in her left breast, and the breast was amputated. Soon after the operation large veins appeared in the operation scar and persisted. She had never been short of breath, rarely had a cough, and had always done her own housework. The swelling of the arm appeared suddenly about a month previously and was first noticed on awakening in the morning. She had not injured the arm in any way. Massage and electrical treatment at hospital had not produced much improvement.

There were no past or present symptoms that could be ascribed to the high venous pressure in the upper part of the body.

Physical Examination.-The patient was a healthy and well-nourished woman for her years. There was no oedema, cyanosis, or high colour in her face, and mucous membranes were of normal colour and vascularity. Both external jugular veins were very prominent in all positions of the head. Enlarged superficial veins were present over the shoulders and abdomen, and particularly over the chest (Figs. 1 and 2). The left breast had been amputated, and in the scar line a large vein was present, ending below in a large varix over which a slight venous bruit could be heard. The direction of flow in the collateral veins over the chest and abdomen was downwards towards the inguinal region. No glands or other masses were felt in the axilla, groins, or elsewhere. Enlarged veins were not present over either arm, but an infra-red photograph showed superficial collateral veins over the left scapula region. There was pitting oedema of the left arm and forearm, with slight pitting of the 

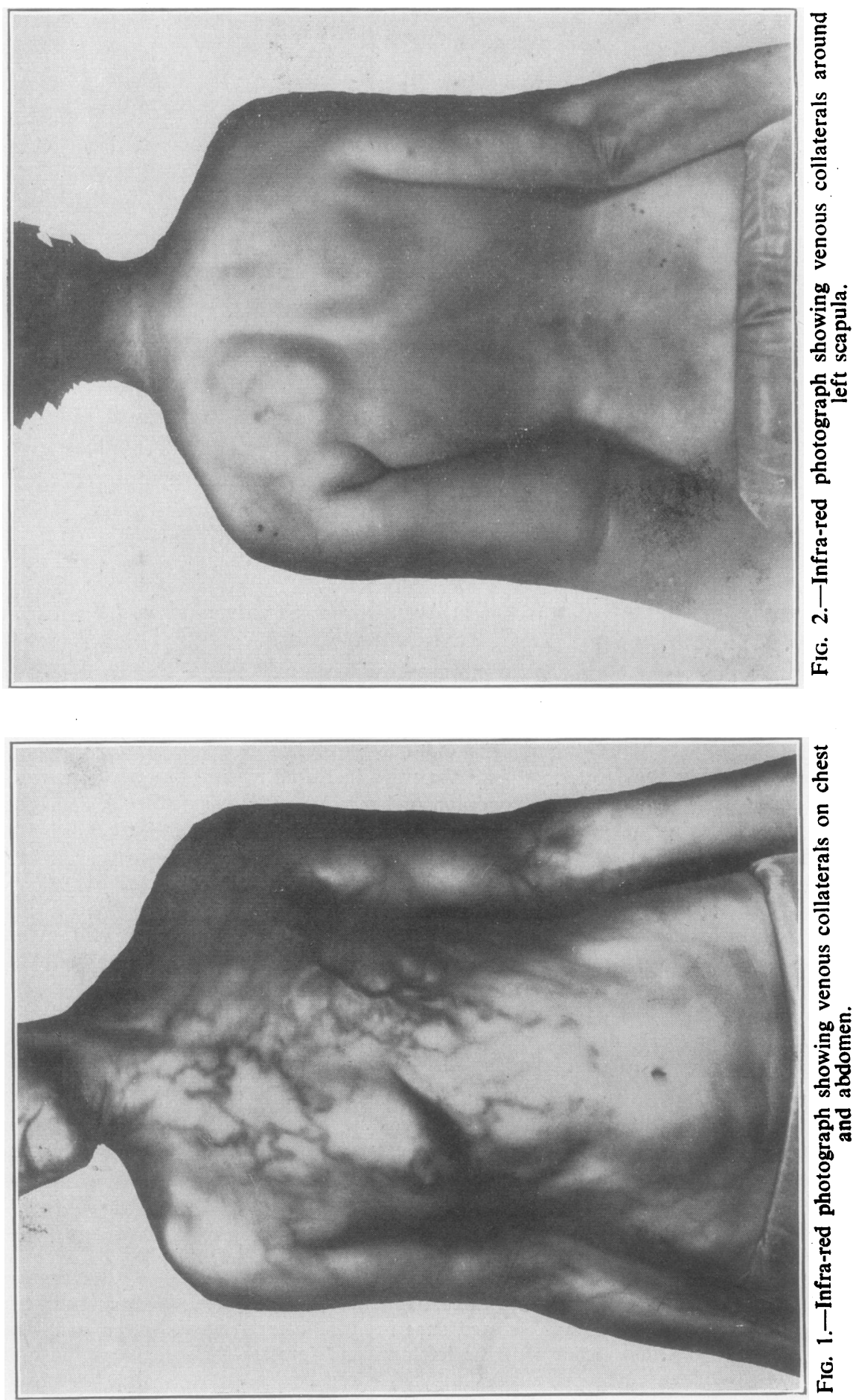
back of the left hand. No evidence of cardiac enlargement could be found, the heart sounds were normal, the lungs clear, and oedema of the legs absent. The blood pressure was $200 / 120$, and the pulse of normal rate and rhythm. The disks showed no enlargement or tortuosity of the veins, and no abnormal signs were found in the nervous system.

The patient was next seen a year later. The general health had remained good, the blood pressure was $160 / 100$, and the condition of the veins was unchanged. The swelling of the left arm had not completely subsided.

\section{LABORATORY INVESTIGATIONS :}

Urine.-The urine was normal.

Blood.-The sedimentation rate was $25 \mathrm{~mm}$. by the Westergren method. There were $36 \mathrm{mg}$. of urea per $100 \mathrm{ml}$., and haemoglobin was $15.0 \mathrm{~g}$. per $100 \mathrm{ml}$., leucocytes 11,000 per c.mm., and the Wassermann reaction and Kahn test were negative.

Circulation rates.-These were: decholin, right side 16 seconds, left side 17 seconds; ether, right side 8 seconds, left side 9 seconds.

Venous pressure. - In the right arm the pressure measured $24 \mathrm{~cm}$. and in the left arm $27 \mathrm{~cm}$. water.

Electrocardiogram-There was some left axis deviation.

Radiological examination.- On the above findings a diagnosis of obstruction to the superior vena cava was made. In the hope of throwing light on the nature of the longstanding block, angiocardiography was attempted, using the technique of Robb and Steinberg (1940). This allows two or three radiographs to be made within a period of 8 to 10 seconds, during which time the big veins, heart, and aorta can be visualized. As an improvement on this technique, the screen was connected to an electric circuit containing a still Leica camera loaded with $35 \mathrm{~mm}$. film, so that a series of miniature radiographs could be taken at intervals of $1 \frac{1}{4}$ seconds. An improvement on this technique is described by Sussman, Steinberg, and Grishman (1941). As in the original Robb and Steinberg technique, $35 \mathrm{ml}$. of 60 per cent diotrast (70 per cent was not available) was injected through a wide-bore needle into a right antecubital vein within $1 \frac{1}{2}$ seconds, the arm being extended above the head, and a consecutive series of 20 exposures being commenced towards the end of the injection. The patient developed a feeling of heat passing over the body, but there were no other untoward symptoms.

Radiological Report (Dr. H. Wormald).-The first film (Fig. 3) shows the dye in the axillary and subclavian veins, the shadow of the latter terminating abruptly at the point where it joins the internal jugular to form the innominate vein. In addition, dilated and tortuous collaterals are seen on the lateral chest wall, extending downwards from the axilla and over the lower chest in the region of the diaphragm. These probably represent the lateral thoracic, thoraco-epigastric, and phrenic veins, together with numerous other superficial veins of the thorax and upper abdomen. Later films in the series (Figs. 4 and 5) show a fairly rapid disappearance of the dye from the axillary, the lateral part of the subclavian, and the collateral veins; but the dye remains in the blind medial part of the subclavian vein for a matter of 20 seconds. Owing to the position of the patient's right arm, and the fact that the vein was rising as it passed laterally over the first rib, the dye which had entered the blind end at the time of the injection did not drain back freely into the collateral circulation. The slow disappearance of this shadow excluded the possibility of a free communication between the medial end of the subclavian and the internal jugular vein, and the sharply cut off appearance indicated an intraluminal rather than an extraluminal cause of obstruction-viz., thrombus as opposed to extrinsic pressure. The miniature films show no indication of a mediastinal mass, but there is some pleural thickening at the right base. 


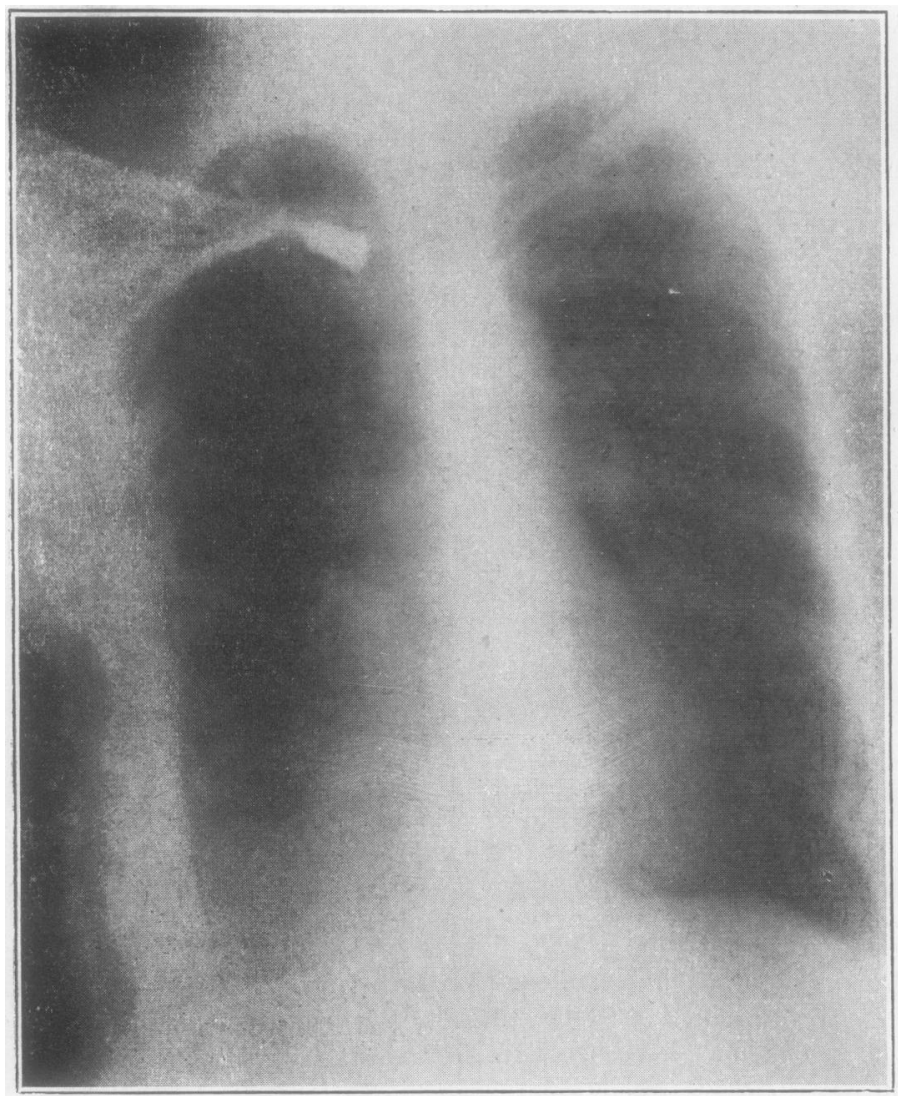

Fig. 3.

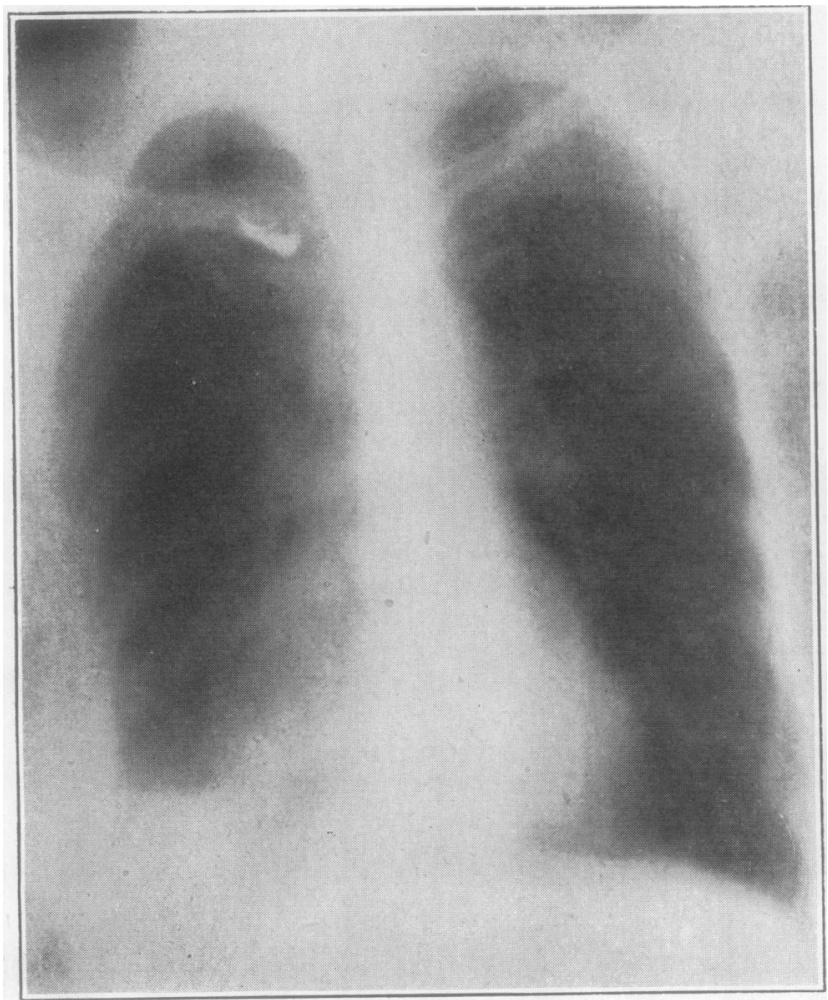

Fig. 5 .

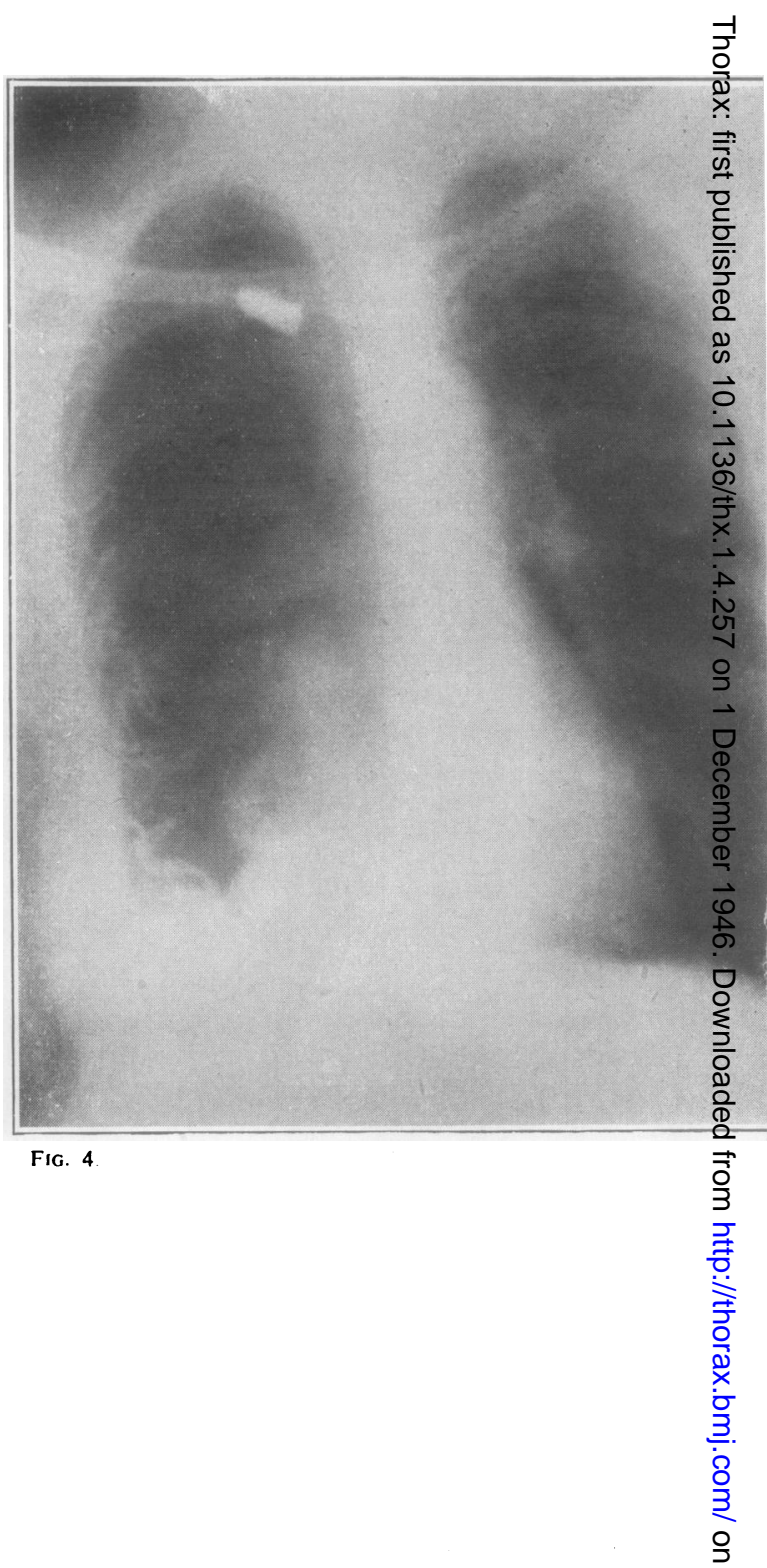

FIG. 3.-Miniature radiograph No. 1, taken toward en of injection.

N.

Fig. 4.-Miniature radiograph No. 2, taken $1 \frac{1}{4}$ ségonc later.

Fig. 5.-Miniature radiograph No. 10, taken $12 \frac{1}{2}$ seéenc after injection. 


\section{Discussion}

Robb and Steinberg (1940), using their original method in 5 cases of obstruction to the superior vena cava, found complete occlusion to be absent in all. In the case described by Soloff (1939), diotrast venography taken at 2 and 6 seconds after the injection showed emptying of the arm veins into the lateral thoracic veins, but the subclavian vein and its continuation were not visualized. Forster (1942) included a diotrast venogram in his case report, and radiographs taken at the termination of the injection and 3 seconds later showed the opaque material in the cephalic vein and passing into the internal mammary veins, but the axillary, subclavian, and larger veins were not visualized. I have found no other case in the literature where radiographs defined the periphery of the blocked area. From the clinical features of the case described here, either both innominate veins are blocked, or more likely the thrombus extends from the termination of the subclavian vein into the superior vena cava itself. It is impossible from the history to ascertain the cause of the original lesion in childhood. The thrombosis of the left arm veins, together with the amputated breast on the same side, suggested at first glance secondary deposits as a cause of the oedema of the arm. However, no evidence of such deposits could be found, and the breast had been removed 20 years previously. Spontaneous thrombosis in an area of venous stasis is to be expected, especially in an elderly person. Bailley (1854) described thrombosis of the collateral veins on the chest as a complication in a case of thrombosis of the superior vena cava due to a mediastinal tumour. Both decholin and ether circulation-times in the present case are just within the limits of normality.

There seems to be no agreement whether the circulation in the upper part of the body is slowed in cases of obstruction to the superior vena cava. Lian and Abaza (1935) state that a high venous pressure in the arms, a normal venous pressure in the legs, and a normal circulation time is diagnostic of the condition, but Soloff (1939) and Gray and Skinner (1941) describe a prolongation of the circulation-time. The collateral channels produced in block of the superior vena cava depend upon whether the obstruction is above or below the entrance of the vena azygos major. In the former case the main collaterals open into the patent part of the vena cava below the block, and the collateral circulation is relatively direct. Under such conditions one might expect the circulation-time not to be greatly altered. In the case here described there were no symptoms referable to the blocked vessel. This was probably due to the obstruction having been present since early life, and the circulation having presumably kept pace with growth and development. With adequate deep collateral channels it is possible for the superficial vessels not to be obviously dilated. This seems to have been the case in the old man of 93 years of age described by Blasingame (1938). The condition was discovered during routine dissection, the superficial veins were not dilated, and no clinical history was available. In the case described by Kammer 
(1943) in a negro of 20 years of age, collateral vessels had been present since the age of 12 , and the subject was healthy and had never shown symptoms. René Martin et al. (1934) describe a patient still alive after a history of 17 years, during the greater part of which there had been no symptoms. The longest period of survival noted in the literature is 31 years (Claverie, 1858).

\section{SUMMARY}

1. A case of symptomless occlusion of the superior vena cava of at least 50 years' duration is described. Spontaneous thrombosis of the veins of one arm was present.

2. The superficial collateral veins were demonstrated by infra-red photography, and the presence of a block in the venous system by a venogram.

3. Venous hypertension was present in the arms, but the circulation-time lay within normal limits.

\section{REFERENCES}

Bailley (1854). Bull. Soc. anat. Paris, 29, 61.

Blasingame, F. J. L. (1938). Arch. Pathol., 25, 361.

Claverie, G. E. (1858). Thèse de Paris, No. 26.

Forster, D. E. (1942). Clinics, 1, 591.

Gray, H. K., and Skinner, I. C. (1941). Surg. gynec. obstet., 72, 923.

Kammer, V. (1943). E. Afr. med. J., 20, 317.

Lian, C., and Abaza, A. (1935). Bull. Mém. Soc. méd. Hôp. Paris, 51, 730.

Martin, René, Rouëssé, and Fiocconi (1934). Ibid., 50, 192.

Ochsner, A., and Dixon, J. L. (1936). J. Thorac. Surg., 5, 641.

Robb, G. P., and Steinberg, I. (1940). J. Amer. med. Ass., 114, 474.

Soloff, L. A. (1939). Amer. Heart. J., 18, 318.

Sussmann, M. L., Steinberg, M. F., and Grishman, A. (1941). Amer. J. Roentgen., 46, 745. 